\title{
RESEARCH AND DEVELOPMENT OF COMBUSTION ENGINE FOR MICRO-COGENERATION UNIT
}

\author{
Marián Polóni, Ján Lach, Andrej Chríbik \\ Slovenská Technická Univerzita (STU) v Bratislave \\ Strojnicka fakulta \\ Námestie slobody 17, 81231 Bratislava, Slovakia \\ tel.:+421903 194510, +421257296490, +421257296400 \\ e-mail:marian.poloni@stuba.sk \\ jan.lach@stuba.sk,andrej.chribik@stuba.sk
}

\begin{abstract}
The paper deals with research and development of original small-size internal combustion engine Lombardini LGW 702. This engine was optimised for application in micro-cogeneration unit (MCU), equipped with variable-speed generator and electronic converter. The electronically controlled combustion engine in MCU works in a regime depending on the load of the generator. It has the lowest possible number of revolutions and minimum possible fuel consumption. The generator combines directly with the crankshaft of the engine. To reach stable parameters of the network, the power electronics controls and processes the variable frequency of the generator. A combustion engine powered by natural gas can utilise also a blend of natural gas and hydrogen and other alternative fuels produced from renewable sources of energy, e.g. synthesis gases. A comparison of engine parameters was made, namely parameters of engines powered by the above-mentioned alternative fuels, such as syngas, coke-oven gas, landfill gas, sewer gas, Hythane and natural gas. A new three-phase variable-speed generator and converter for micro-cogeneration unit were developed. The rated electric power of $M C U$ is $4 \mathrm{~kW}$. The power overload is $80 \%$, compared to rated power. In the case of natural gas, the best electric efficiency is $25 \%$, the thermal efficiency is $65 \%$ and the total efficiency of MCU is more than $90 \%$.
\end{abstract}

Keywords: combustion engine optimisation, micro-cogeneration unit, alternative fuels

\section{Introduction}

A combination of combustion engine with variable-speed generator of electric energy represents a modern way of producing electric energy and heat allowing to control the system power not only via changes of load in a given revolution regime but also via change of revolutions of the engine. To obtain exquisite MCU parameters requires in a given range of revolutions to reach maximum power parameters of the combustion engine together with a high value of efficiency of the generator and power converter. The spark-ignition combustion engine Lombardini LGW 702, powered mainly with natural gas, has been chosen as an object of mechanical demonstration. The engine was optimised by changed compression ratio, by changes in the shape of combustion chamber, by changes in timing of valves, by tuning the geometry of intake manifold, by design and choice of a suitable gas mixer, by optimisation of the moment of ignition, by a new ignition system and electronic preparation of mixture composition. The parameters of the engine were tuned to revolutions $1800 \mathrm{~min}^{-1}$ to satisfy the condition that the revolution range of permanent work done by the motor should be 1300-2000 $\min ^{-1}$. The maximum number of revolutions of continuous work of the engine is limited by values of temperature of exhaust gases that should not exceed $640{ }^{0} \mathrm{C}$ to secure a long lifetime of the engine. The variable-speed generator and the converter have been designed for the electric load $4 \mathrm{~kW}[1]$. The results listed hereinafter are from the first measurements taken from a functional prototype of $\mathrm{MCU}$ and some results are also presented from modelling of the engine powered by synthesis gases. 


\section{Combustion engine Lombardini LGW 702 - basic adjustments}

The combustion engine Lombardini LGW 702 is an in-line, spark-ignition, four-stroke twocylinder water-cooled combustion engine, with piston primarily designed for applications utilising natural gas. This engine was derived from a diesel combustion engine Lombardini LDW 702. The elements of the originally diesel combustion engine that were adjusted to obtain a gas sparkignition combustion engine were ordered from the Italian producer. The basic parameters of the combustion engine Lombardini LGW 702 are given in Tab. 1.

The producer of the engine has performed adaptations as follows:

- replacement of the original head of the diesel-engine version of the combustion engine for the head with openings for installing spark plugs,

- decrease of compression ratio to $12.5: 1$, realised by replacement of the original pistons for pistons with a cavity in the bottom of the pistons of the requested volume and shape,

- supply of original intake manifold with common container and electronically controlled throttle.

Tab. 1. Basic parameters of combustion engine Lombardini LGW 702

\begin{tabular}{|l|c|}
\hline Crankshaft throw angle $\left[{ }^{\circ}\right]$ & 360 \\
\hline Swept volume $\left[\mathrm{cm}^{3}\right]$ & 686 \\
\hline Bore/ Stroke $[\mathrm{mm}]$ & $75 / 77.6$ \\
\hline Compression ratio $[-]$ & $12.5: 1$ \\
\hline Valve gear/ Drive & OHC/Belt drive system \\
\hline Fuel & Natural gas (and alternative gases) \\
\hline Lubrication system & Pressure circuit, full-flow filtration, oil filling 1.61 \\
\hline
\end{tabular}

During the procedures at the university (STU), the engine was equipped with a new intake system and a newly designed diffuser, a camshaft with optimised valve timing, a new ignition system, and an electronic system VOILA for mixture preparation [2]. The primary requirement for the system preparing mixture was to optimise the richness of the mixture (air excess ratio approx. $\lambda=1$ ) at revolutions $1800 \mathrm{~min}^{-1}$. The intention was also to optimise the engine from the ecological point of view, namely from the point of optimal composition of mixture within the range of revolutions and loads. For this reason, the system was designed to offer a possibility to supplement electronic control of mixture preparation (possible supplementation electronically, with the help of a signal from the control unit of the controlled regulatory valve fitted in the supply of fuel to the mixer). The body of the mixer was designed to aid simplicity of production, montage, but most of all to aid simple exchange of diffusers during the process of optimisation of the combustion engine. To find out the impact of particular diffusers on the parameters of combustion engine, with the aim to determine the optimum diffuser, the combustion engine Lombardini LGW 702 was experimentally measured with a dynamometer MEZ Vsetín, type 1DS736V, in the laboratory at STU. There were four mixers devised for the combustion engine. The measured and calculated parameters of the combustion engine were reduced to standardised measurement conditions: atmospheric pressure $101325 \mathrm{~Pa}$ and atmospheric temperature $20^{\circ} \mathrm{C}$. The results pertaining to the measurements are listed in Fig. 1 and Fig. 2.

A comparison of power in Fig. 1 documents a positive impact of electronic control of mixture composition $(\lambda=1)$ on increased power, especially in the range of higher revolutions. Based on this comparison of the diagrams (Fig. 1, Fig. 2), as the best diffuser for the engine Lombardini LGW 702 was chosen the diffuser of the mixer with the diameter $17 \mathrm{~mm}$, as it had demonstrated the best results in the area of partial loads, where the combustion engine would also work in the case of low electric power. Besides, this diffuser works at $1800 \mathrm{~min}^{-1}$ with large enough reserve for required electric power. 


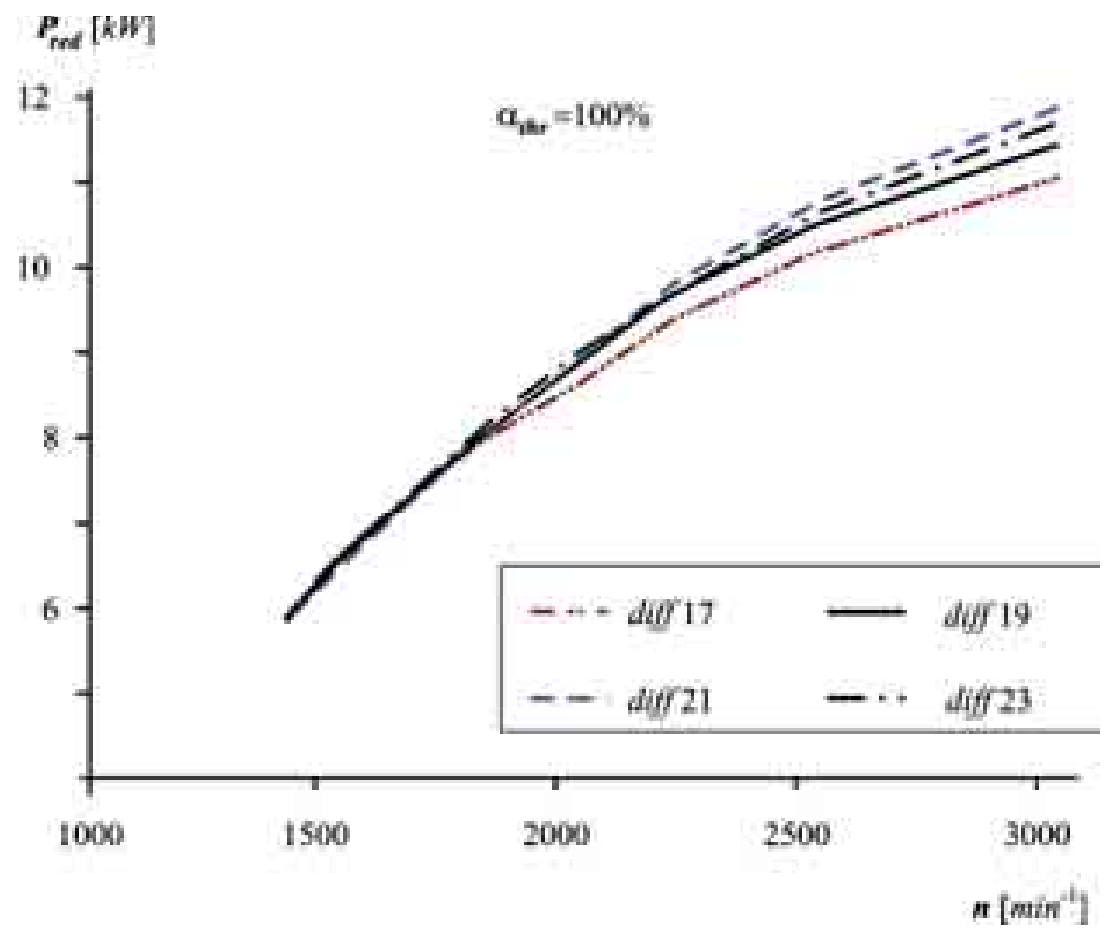

Fig. 1. Lombardini LGW 702 - comparison of reduced power $\boldsymbol{P}_{\boldsymbol{r e d}}$ with changing revolutions $\boldsymbol{n}$ of combustion engine, the throttle is open to $\alpha_{t h r}=100 \%$, various diffusers (diameters from 17 to $23 \mathrm{~mm}$ ), the mixture is electronically controlled $(\lambda=1)$, original intake manifold

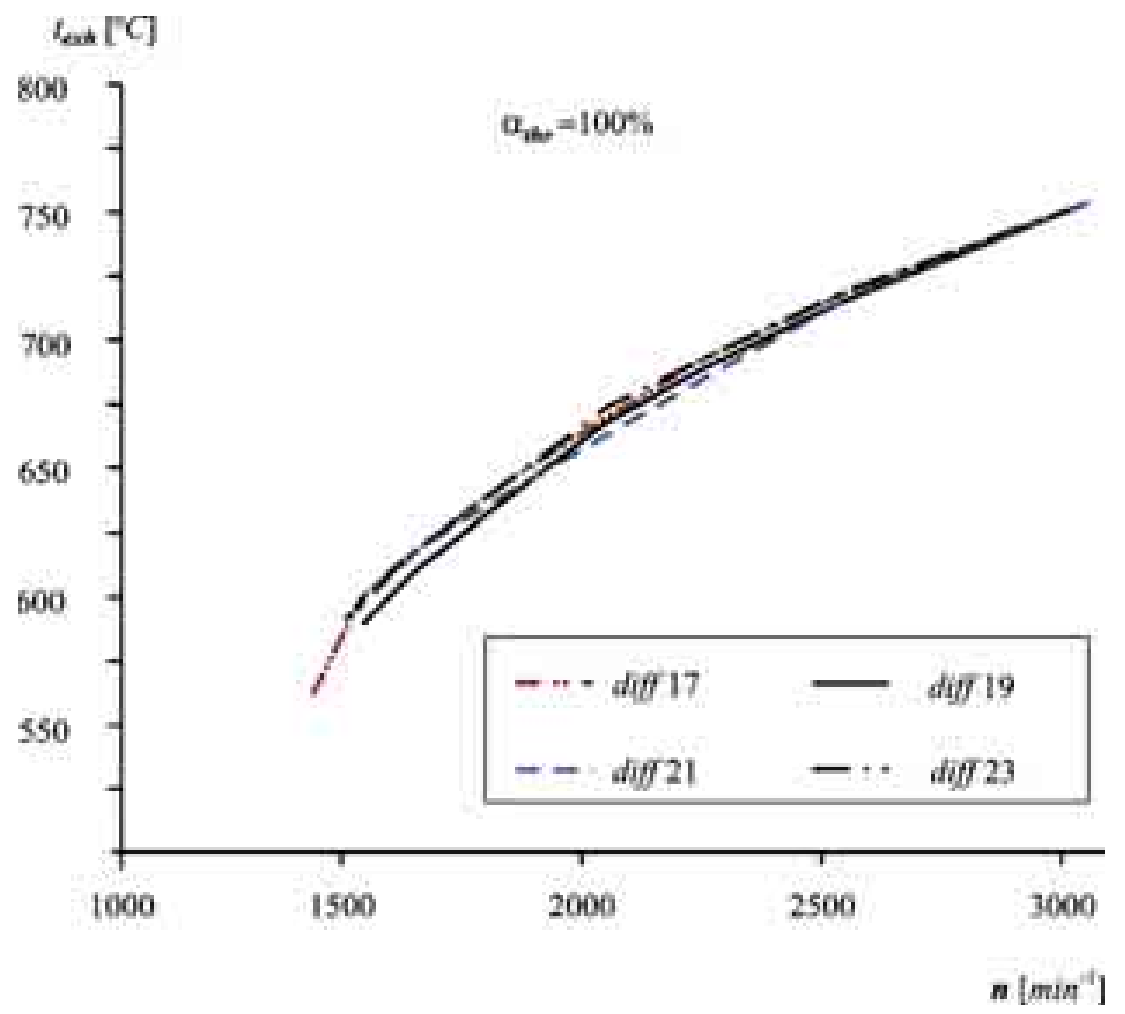

Fig. 2. Lombardini LGW 702 - comparison of temperatures of exhaust gases $\boldsymbol{t}_{\boldsymbol{e x h}}$, the throttle is open to $\alpha_{\text {thr }}=100 \%$, various diffusers, with changing revolutions $\boldsymbol{n}$ of combustion engine, mixture is electronically controlled $(\lambda=1)$, original intake manifold

During the experiments, the best angle of spark advance before the TDC of the piston was stated the angle $28^{\circ}$. From the point of long lifetime of the combustion engine components, it is rather important to keep the operating parameters in pre-set boundaries. In the gas ignition 
engines, the most overloaded elements are the seats of exhaust valves. To secure their long-time service and the service of the whole MCU, the maximum long-time temperature of exhaust gases has been stated at $640^{\circ} \mathrm{C}$. As can be seen in Fig. 2, the combustion engine Lombardini LGW 702 has the value of the exhaust temperature $640^{\circ} \mathrm{C}$ for revolutions around $1900-2000 \mathrm{~min}^{-1}$.

Based on the results from experiments, a regime of long-time operation of the combustion engine in the range of revolutions from 1300 to $2000 \mathrm{~min}^{-1}$ was determined. The objective of the next research work was to increase the power parameters of the combustion engine Lombardini LGW 702 within the determined regime of revolutions for long-time operation.

\section{Optimisation of gas exchange process and experimental verification of results}

The increase in power parameters of the combustion engine within the range of revolutions from 1500 to $2000 \mathrm{~min}^{-1}$ was acquired by increasing the volumetric efficiency of the combustion engine via optimising the gas exchange process. To find about and investigate into the optimisation of the gas exchange process, a virtual model was developed in the environment of Lotus Engine Simulations, version 5.06 (hereinafter: „LES“). The virtual model of the combustion engine is depicted in Fig. 3, with a description of its manifold system and other elements.

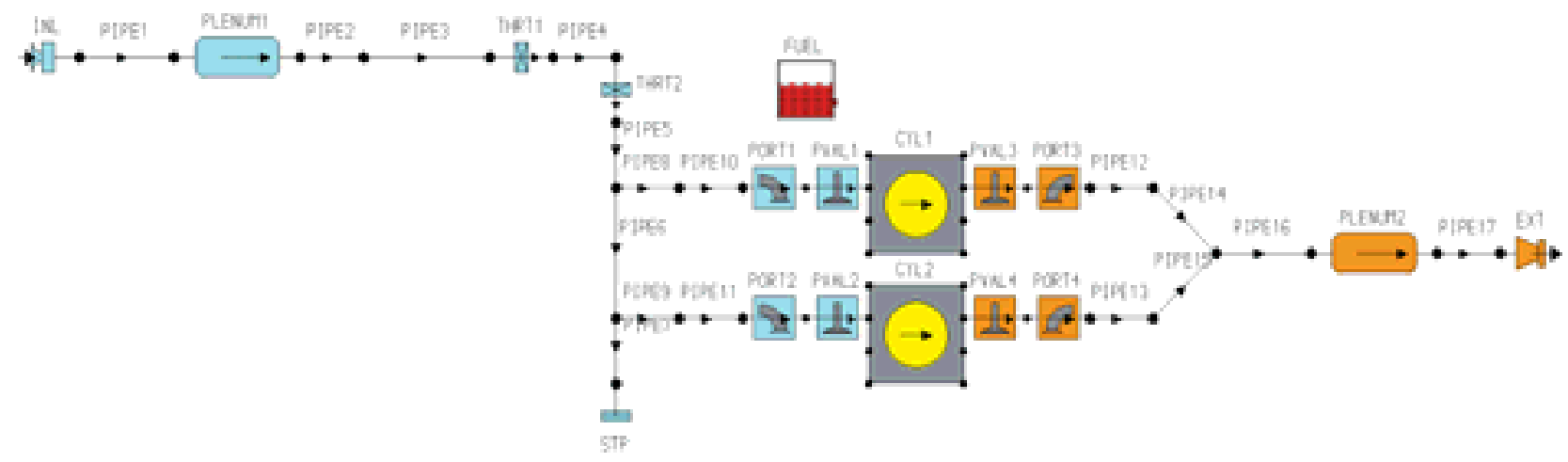

Fig. 3. Virtual model of the combustion engine Lombardini LGW 702, created with the program LES

The data necessary for virtual modelling of the engine were taken from accessible data on the engine. Some of the data, as for example port flow coefficients, together with valves, throttle flow coefficients and values of mechanical efficiency of the engine in various regimes of the engine, were acquired by experiments.

The analysis of flow in the intake manifold, after performed simulation calculations, has shown that the process of gas exchange is accompanied by two negative events. The first negative phenomenon is a backflow of hot exhaust gases from the cylinder to the suction pipe at the beginning of the suction process, which brings the risk of self-inflammation of fresh mixture, composed of natural gas and air in the intake manifold. The second negative phenomenon is a massive backflow from the cylinder at the end of the suction process. There is an evidence of both of these phenomena in temperature curves in Fig. 4 and in mass flow of the mixture to the cylinder in Fig. 5. Fig. 4 shows a step increase of temperature in the moment of opening of the inlet valve (IVO) during the valve overlap period.

Figure 5 shows mass flow rate of the inlet gases to the cylinder. It can be seen that in the moment just before closing the inlet valve (IVC), there occurs a massive backflow of the mixture from the full cylinder, which leads to lower filling efficiency.

The above-mentioned negative phenomena can be rid of or, better to say, are suppressed by suitably designed timing of the inlet valve. With the aim to utilise the laws of unsteady flow and to increase the volumetric efficiency of each cylinder, several models of the optimisation process of gas exchange were suggested that had been calculated with parametric optimisation. The result 


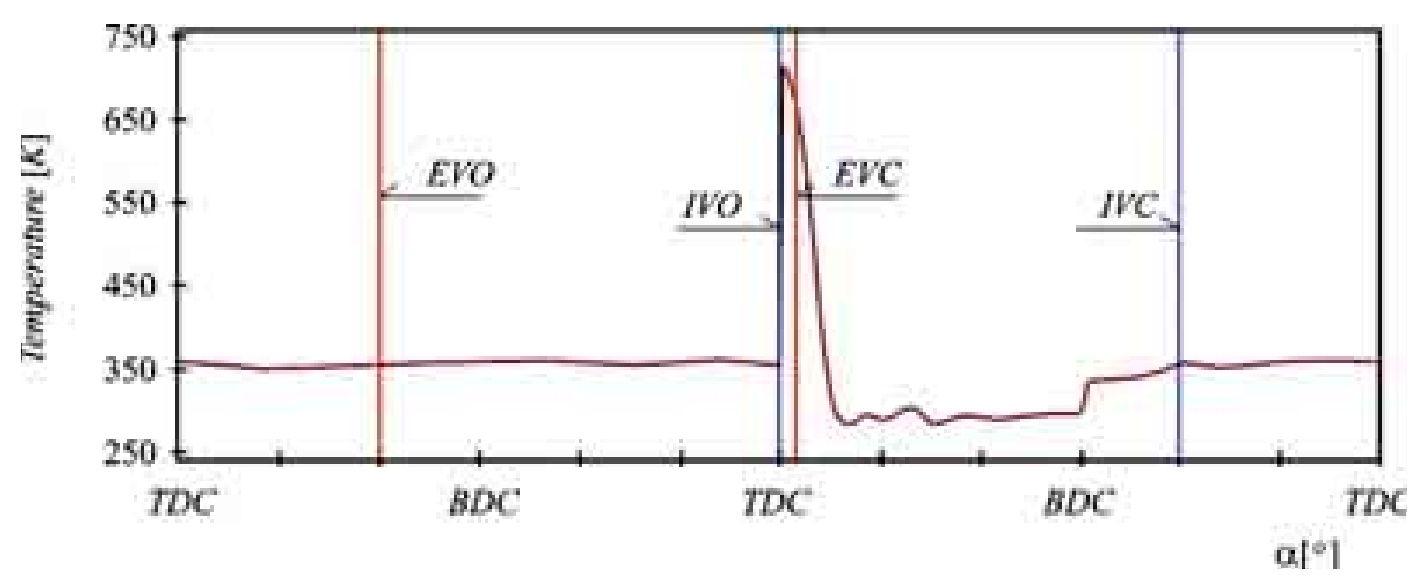

Fig. 4. Lombardini LGW 702 - model course of temperature at inlet valve of the first cylinder at revolutions $1800 \mathrm{~min}^{l}$, original timing. TDC - top dead centre, BDC - bottom dead centre, IVO - inlet valve opening, $I V C$ - inlet valve closing, EVO-exhaust valve opening, EVC-exhaust valve closing, $\alpha$ - crankshaft angle

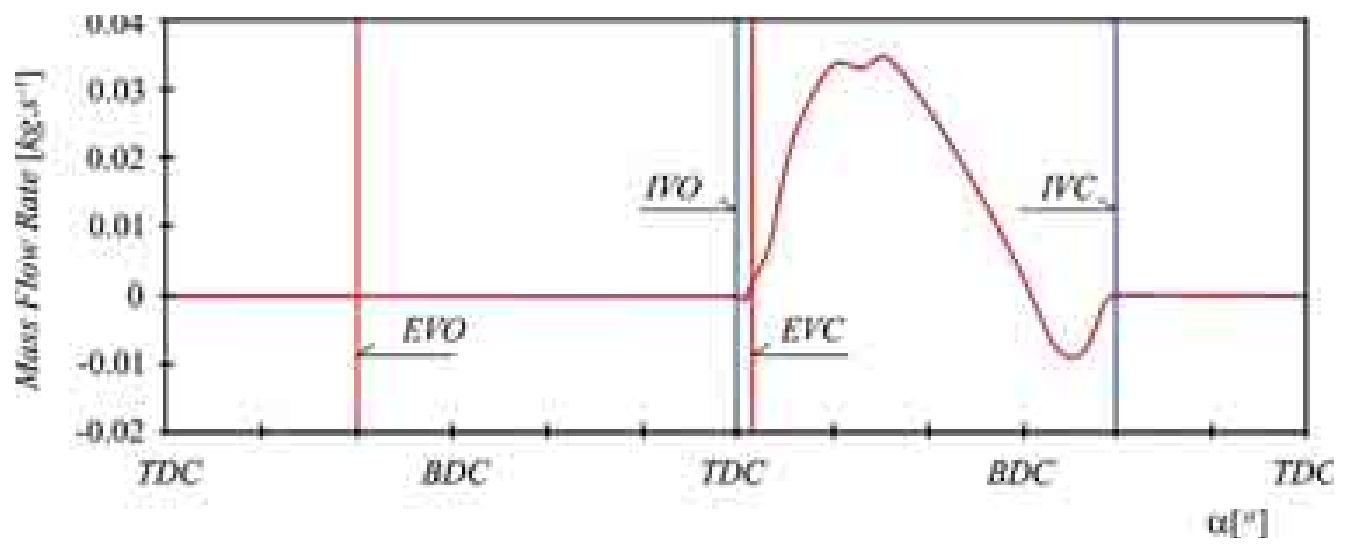

Fig. 5. Lombardini LGW 702 - model course of mass flow rate at inlet valve of the first cylinder at revolutions 1800 min $^{-1}$, original valve timing

was the design and later production of the following elements that improved optimisation of gas exchange:

- a change of geometry of the intake manifold by prolonging its branches between the head of the combustion engine and the common vessel in the intake manifold,

- an optimisation of valve timing.

A prolonged intake manifold represents a simple way how a construction of intake manifold can be changed. The result of the optimisation is a change of the distance between the head of the combustion engine and the common vessel in the intake manifold to $650 \mathrm{~mm}$. A change of valve timing is also a simple way how to adjust parameters of combustion engine, when the original camshaft is changed for a newly produced camshaft with optimised timing. This optimised timing of valves was adapted before the camshaft was produced, with respect to production availabilities of the producer of the camshaft. That is the reason why in the final phase of optimisation of gas exchange, two versions of timing were verified, that is (measured values):

Version 1: $\quad$ IVO $13^{\circ}$ after TDC EVO $55^{\circ}$ before BDC,

IVC $47^{\circ}$ after BDC EVC $2^{\circ}$ after TDC, valve lift $5.9 \mathrm{~mm}$ valve lift $8 \mathrm{~mm}$.

Version 2: $\quad$ IVO $7^{\circ}$ before TDC EVO $30^{\circ}$ before BDC, IVC $49^{\circ}$ after BDC EVC $29^{\circ}$ after TDC, valve lift $8 \mathrm{~mm}$ valve lift $8 \mathrm{~mm}$.

The effect of prolonged intake manifold, combined with the effect of changed timing (Version 2) on the course of volumetric efficiency is in Fig. 6. Such a combination of length of manifold with 
timing was used in the final version of the engine for MCU. From the picture it can be seen that optimisation of the process of gas exchange has brought about improved filling of cylinders within the revolution range $1400-1800 \mathrm{~min}^{-1}$ by $5-6 \%$, at maximum revolutions even by $9 \%$.

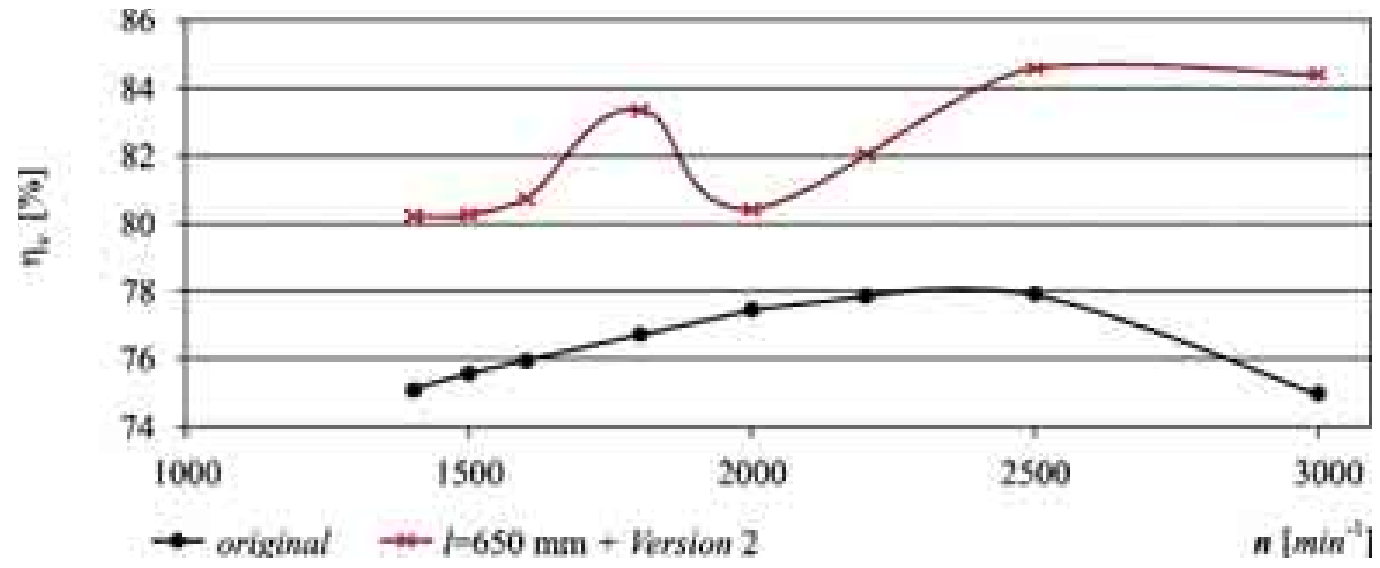

Fig. 6. Lombardini LGW 702 - comparison of courses of volumetric efficiency $\boldsymbol{\eta}_{\boldsymbol{v}}$, depending on engine revolutions $\boldsymbol{n}$, with optimised valve timing in combination with the original length of manifold (blue curve) and with the optimised length of manifold (red curve)

Figure 7 documents the effect of the change in configuration of the intake manifold alongside with the change in timing of valves to reduced effective power of the combustion engine Lombardini LGW 702.

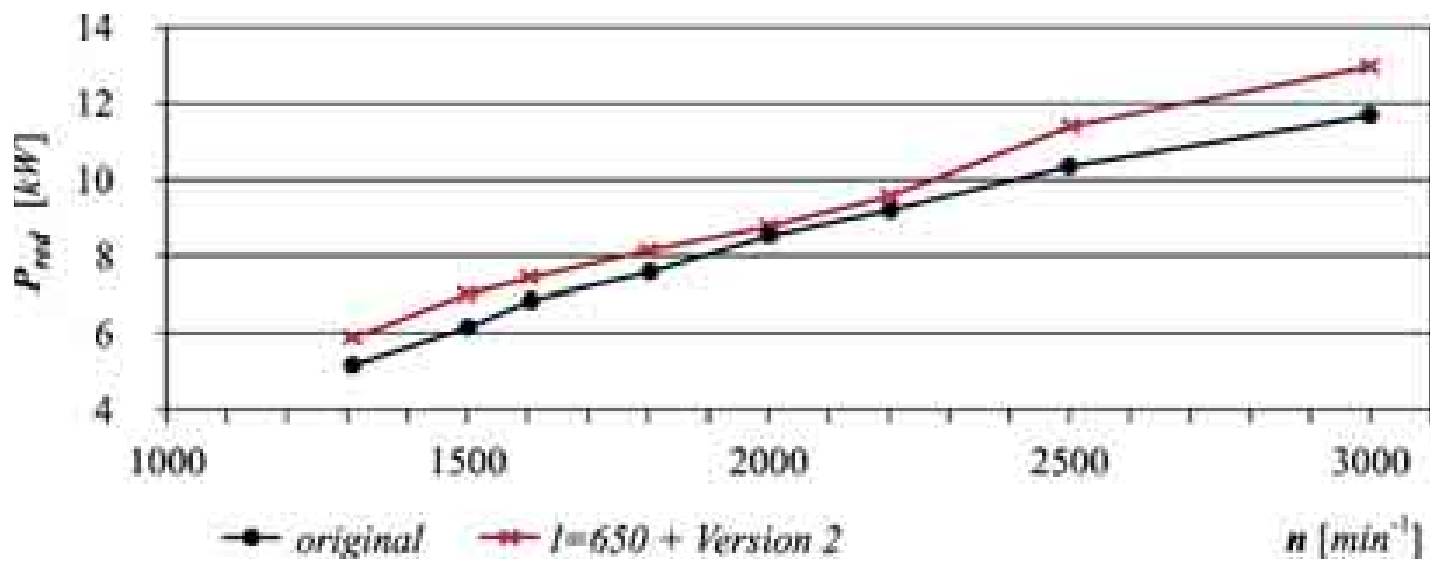

Fig. 7. Course of reduced effective power $\boldsymbol{P}_{\text {red }}$ (measured values) of the engine Lombardini LGW 702 as depending on engine revolutions $\boldsymbol{n}$, fuel - natural gas, $\alpha_{t h r}=100 \%$, diffuser $\emptyset_{\text {dif }}=17 \mathrm{~mm}, \varepsilon=12.5$; valve timing Version 2; mixture composition controlled to $\lambda=1$

The adjustments of the combustion engine can be summarised in the following way. The optimisation of the combustion engine has led to general improvement of power parameters in the range of operating revolutions from 7 to $14 \%$. This allows the cogeneration unit to work at a given electric power, with lower revolutions of the engine by about $150-200 \mathrm{~min}^{-1}$, compared to the original setting of the engine (Fig. 7). As a result, at the required electric power, the MCU saves on the consumed fuel from 5 to $10 \%$, depending on the actual regime of the engine.

\subsection{Lombardini LGW 702 powered by alternative fuels}

The following Tab. 2 gives the basic properties of gaseous alternative fuels, which can be used as a fuel for a micro-cogeneration unit. The greatest lower calorific value (LCV), related to $1 \mathrm{~kg}$ of fuel pertains to a mixture of natural gas and hydrogen (Hythane), and the lowest pertains to 
syngas, because the main component of this gas is carbon monoxide $(\mathrm{CO})$, whose calorific value is about $10 \mathrm{MJ} \cdot \mathrm{kg}^{-1}$. The calorific value of stoichiometric air-fuel mixture (CV of AF mixture) has the highest value pertaining to natural gas $\left(97 \% \mathrm{CH}_{4}, 1.4 \% \mathrm{C}_{2} \mathrm{H}_{6}, 0.4 \% \mathrm{C}_{3} \mathrm{H}_{8}, 0.2 \% \mathrm{C}_{4} \mathrm{H}_{10}, 0.2 \%\right.$ $\mathrm{CO}_{2}, 0.8 \% \mathrm{~N}_{2}$ ), and the lowest value pertaining to syngas, which is produced by gasification (with movable grate of gasifier) from municipal waste. The lowest density or the molar mass determined under normal conditions $\left(20^{\circ} \mathrm{C}, 101325 \mathrm{~Pa}\right)$ can be found with the coke-oven gas, because the gas contains $57 \%$ vol. of hydrogen. The atomic ratio of hydrogen to carbon $(\mathrm{H} / \mathrm{C})$ is the highest for coke-oven gas and the lowest ratio is for syngas because syngas contains only $24 \%$ vol. of $\mathrm{H}_{2}$ or $5 \%$ vol. of $\mathrm{CH}_{4}$. The highest ratio of oxygen to carbon $(\mathrm{O} / \mathrm{C})$ has a mixture called syngas, because it contains $40 \%$ vol. $\mathrm{CO}$ and $26 \%$ vol. $\mathrm{CO}_{2}$. The specific gas constant $\mathrm{R}_{\text {specific }}$ is the lowest for landfill gas, which results from molar mass of landfill gas.

Tab. 2. Basic properties of selected gaseous alternative fuels

\begin{tabular}{|c|c|c|c|c|c|c|c|}
\hline \multicolumn{2}{|c|}{ Type of gas fuel } & Syngas & Coke-oven gas & Landfill gas & Sewer gas & Hythane & Natural gas \\
\hline \multicolumn{8}{|c|}{ Gas composition } \\
\hline $\mathrm{CH}_{4}$ & {$[\%$ vol. $]$} & 5 & 30 & 52 & 69 & 80 & 97 \\
\hline $\mathrm{H}_{2}$ & {$[\%$ vol. $]$} & 24 & 57 & 0 & 0 & 20 & - \\
\hline $\mathrm{CO}$ & {$[\%$ vol. $]$} & 40 & 6 & 1 & 0 & - & - \\
\hline $\mathrm{CO}_{2}$ & {$[\%$ vol. $]$} & 26 & 2 & 27 & 27 & - & 0.2 \\
\hline $\mathrm{N}_{2}$ & {$[\%$ vol. $]$} & 5 & 5 & 20 & 4 & - & 0.8 \\
\hline \multicolumn{8}{|c|}{ Basic properties } \\
\hline $\mathrm{LCV}$ & {$\left[\mathrm{kJ} \mathrm{kg}^{-1}\right]$} & 8345 & 38809 & 16033 & 22959 & 50916 & 48825 \\
\hline CV of AF mixture & {$\left[\mathrm{kJ} \cdot \mathrm{m}^{-3}\right]$} & 2588 & 3023 & 2905 & 3030 & 3122 & 3135 \\
\hline Density & {$\left[\mathrm{kg} \cdot \mathrm{m}^{-3}\right]$} & 1.036 & 0.412 & 1.067 & 0.987 & 0.582 & 0.705 \\
\hline Molar mass & {$\left[\mathrm{kg} \cdot \mathrm{kmol}^{-1}\right]$} & 25.33 & 10.07 & 26.11 & 24.14 & 13.72 & 16.64 \\
\hline $\mathrm{H} / \mathrm{C}$ & {$[-]$} & 0.96 & 6.16 & 2.62 & 2.86 & 4.42 & 3.93 \\
\hline $\mathrm{O} / \mathrm{C}$ & {$[-]$} & 1.3 & 0.27 & 0.69 & 0.57 & 0.004 & 0.004 \\
\hline $\mathrm{R}_{\text {specific }}$ & {$\left[\mathrm{J} \cdot \mathrm{kg}^{-1} \cdot \mathrm{K}^{-1}\right]$} & 328.2 & 837.9 & 318.5 & 345.4 & 606.0 & 499.7 \\
\hline Air-fuel ratio (AFR) & {$\left[\mathrm{m}^{3} \cdot \mathrm{m}^{-3}\right]$} & 2.34 & 4.42 & 4.91 & 6.66 & 8.49 & 9.98 \\
\hline
\end{tabular}

The Fig. 8 shows the course of the reduced effective engine power $\mathrm{P}_{\text {ered }}$ versus revolutions n of modified internal combustion engine LGW 702 (optimised intake manifold, valve timing - version 2) for a variety of alternative gaseous fuels. As can be seen from both the measured and calculated values of power, the characteristics of the course follows the characteristics of the volumetric efficiency (Fig. 6), where we see two local maxima at revolutions $1800 \mathrm{~min}^{-1}$ and at $2500 \mathrm{~min}^{-1}$. The highest power has been reached by the engine running on natural gas, and conversely the lowest one by the engine running on landfill gas, which contains $47 \%$ vol. of inert gas. On average the model expected drop in performance of the engine burning landfill gas is at low speed $28 \%$ and at high speed $33 \%$. Conversely, the lowest drop in power is with the engine running on mixture of Hythane. In that case, the engine power drop is on average $1 \%$ lower compared with the combustion of natural gas. This fact was confirmed by measuring at which the drop in power of the engine burning a mixture of Hythane is on average $2.5 \%$ lower, compared with the engine running on pure natural gas. Compared with pure natural gas, the other gases have reached a decrease in power as follows: syngas $(21.5 \%-24.5 \%)$, cokeoven gas $(18.0 \%-19.6 \%)$, sewer gas $(7.0 \%-10.0 \%)$. The largest differences in engine power are at the highest revolutions. 


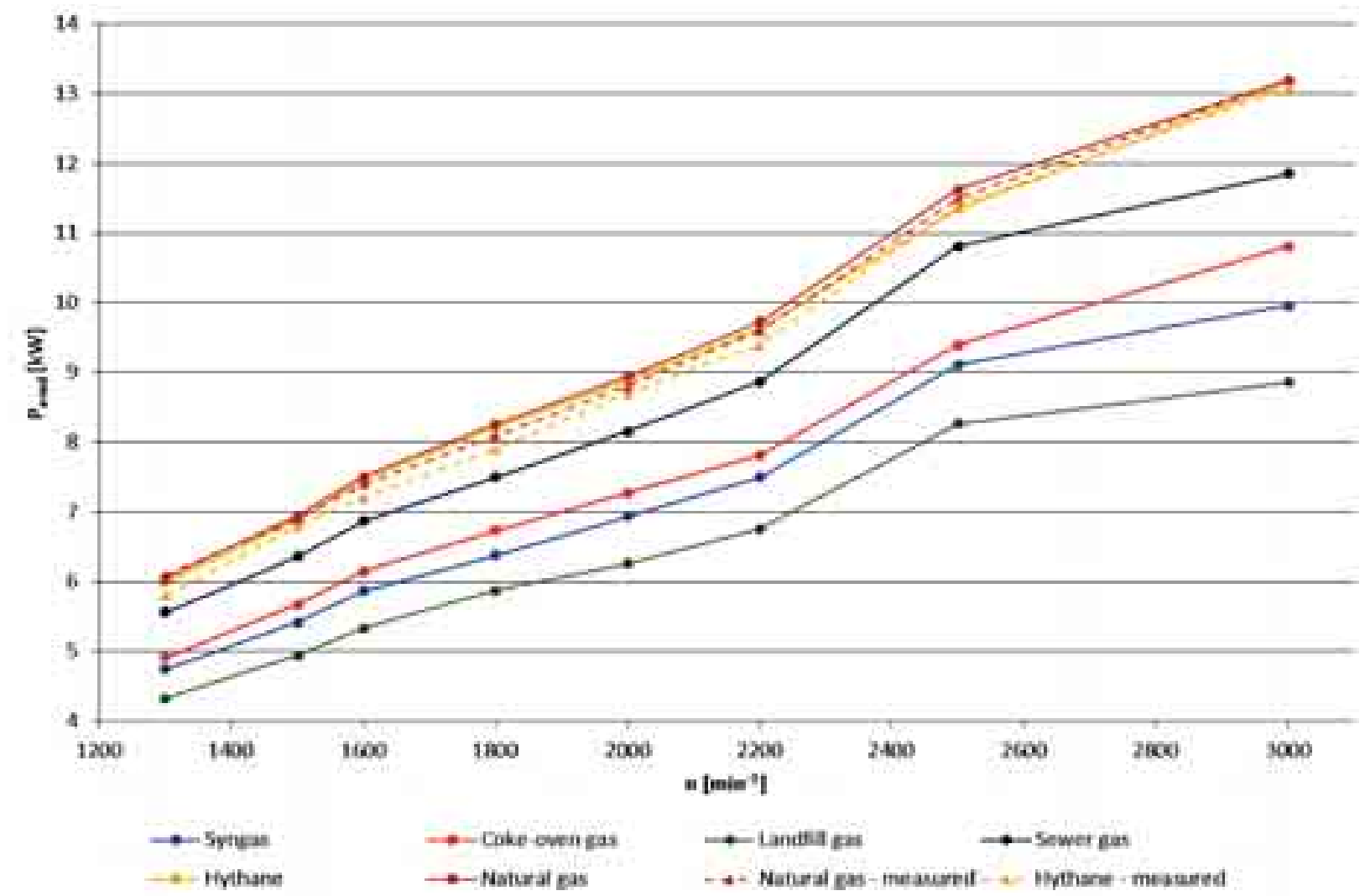

Fig. 8. The course of the reduced effective power $\boldsymbol{P}_{\text {ered, }}$ calculated and measured, depending on revolutions $\boldsymbol{n}$ of the modified internal combustion engine LGW 702 running on a variety of alternative gaseous fuels listed in Tab. 2, under full load, stoichiometric mixture and spark advance $28^{\circ}$

\section{Development of variable-speed generator and converter for micro-cogeneration unit}

Within the development of the micro-cogeneration unit, a three-phase generator with variable speed was designed especially for the micro-cogeneration unit, i.e. a rotor with permanent magnets, without any need of excitation windings, and a stator with 12 poles. The generator can be operated at various speeds, which causes variation of frequency as well as variation of output voltage. The output voltage characteristic, i.e. input voltage for power electronics, was matched to the module of a converter.

On the basis of the performed measurements of the generator and taking into account the characteristics of the combustion engine, it is possible to determine the rated parameters of the generator as follows:

- rated current $\mathrm{IN}=13 \mathrm{~A}$ (for passive cooling),

- rated voltage $\quad \mathrm{UN}=241 \mathrm{~V}$ (line value when connected to star, open-circuit value $249 \mathrm{~V}$ ),

- rated speed $\quad \mathrm{nN}=1800$ min-1 (predominating part of operation),

- speed minimal $\quad \operatorname{nmin}=1300$ min-1,

- speed maximal $\quad \operatorname{nmax}=3000$ min- 1 ,

- rated frequency $\mathrm{fN}=180 \mathrm{~Hz}$,

- rated output power $\mathrm{PN}=5370 \mathrm{~W}$,

- rated power loss $\Delta \mathrm{P}=262 \mathrm{~W}$,

- rated efficiency $\eta \mathrm{g}=95.3 \%$.

The generator, however, can be operated in the whole range of its revolutions from 1300 up to $3000 \mathrm{~min}^{-1}$, and in the whole range of currents from 0 up to $15 \mathrm{~A}$. The generator is operable, and it meets every expected parameter (additional technical improvements however, are not excluded). More details about the generator are given in [3]. 
Similarly to variable-speed generator, within the development of the micro-cogeneration unit a new converter was designed. However, for the purposes of this article, the expression converter shall denominate a device that converts alternating voltage of given parameters to alternating voltage with different parameters, and in power electronics it is a device used to convert voltage. The aim of the technical solution was to develop a device that would be able to convert energy from a three-phase output voltage generated by a synchronised motor generator with variable revolutions, i.e. variable-speed generator with variable frequency and voltage, to a three-phase voltage $3 \times 230 \mathrm{~V} / 50 \mathrm{~Hz}$, and at the same time to control a micro-cogeneration unit. The produced converter reached its efficiency as to maximum power and maximum revolutions higher than $92 \%$. Once again, more details about the designed convertor are given in [3].

\section{Conclusions}

After separate research and development of three dominant aggregates of the microcogeneration unit, i.e. spark-ignition gas engine, variable speed generator, and $\mathrm{AC} / \mathrm{AC}$ converter, a prototype of the micro-cogeneration unit has been designed. Although each of the described aggregates has been designed especially for the micro-cogeneration unit, the unit itself requires efforts to make an overall design of the unit, design of its heat system, safety, and specification of its requirements for control. The heat system of the unit meets the expected parameters, particularly in the light of relation between expected electrical and thermal output power. The required higher level of thermal power has been reached also by incorporating a condensation heat exchanger (Fig.9) that has a positive impact on the total efficiency of the prime fuel utilisation either. The fuel system of the micro-cogeneration unit has been designed in accordance with safety standard requirements. The results of the effort can be seen in Fig. 9 and Fig. 10 [4].

The overall results from the tests of the design of prototype of micro-cogeneration unit can be summarised as follows:

1. Optimisation of combustion engine for particular application to reach good parameters of micro-cogeneration unit (MCU) is always substantiated. In this particular case, as it has been mentioned in the introduction, the optimisation has been performed as a change in compression ratio, change in the shape of combustion chamber, change in timing of valves, tuning of geometry of intake manifold, design and choice of a suitable gas mixer, optimisation of the moment of ignition, introduction of a new ignition system and electronic preparation of mixture composition. This optimisation has led to general improvement of power parameters in the main range of operating revolutions (1 300-2 000 $\mathrm{min}^{-1}$ ), from 7 to $14 \%$. This allows the cogeneration unit to work at a given electric power with lower revolutions of the engine by about $150-200 \mathrm{~min}^{-1}$, compared to the original setting of the engine. As a result, to produce the required electric power, the MCU saves on the consumed fuel from 5 to $10 \%$, depending on the actual regime of the engine. In the case MCU has a proper and accurate electronic mixture-preparation system, which can keep the air excess ratio $\lambda$ very close to 1 , or just below 1 . Then very low emissions of $\mathrm{CO}, \mathrm{CH}_{\mathrm{x}}$ and $\mathrm{NO}_{\mathrm{x}}$ (Tab. 3.) can be reached.

2. The variable-speed generator has been specially developed for the particular MCU. It is able to operate with the output currents from 0 to $15 \mathrm{~A}$, at revolutions $1300 \mathrm{~min}^{-1}$ up to $3000 \mathrm{~min}^{-1}$. The generator has reached maximum measured efficiency of $95.3 \%$. The generator is operable, and it meets all expected parameters. However, additional technology improvements are not excluded.

3. The converter has been tested in various regimes within island operation, proving the necessity to use additional accumulators to secure positive step-change of load. The measurements have shown a high potential overloading of the converter, exceeding the desired value $80 \%$. 


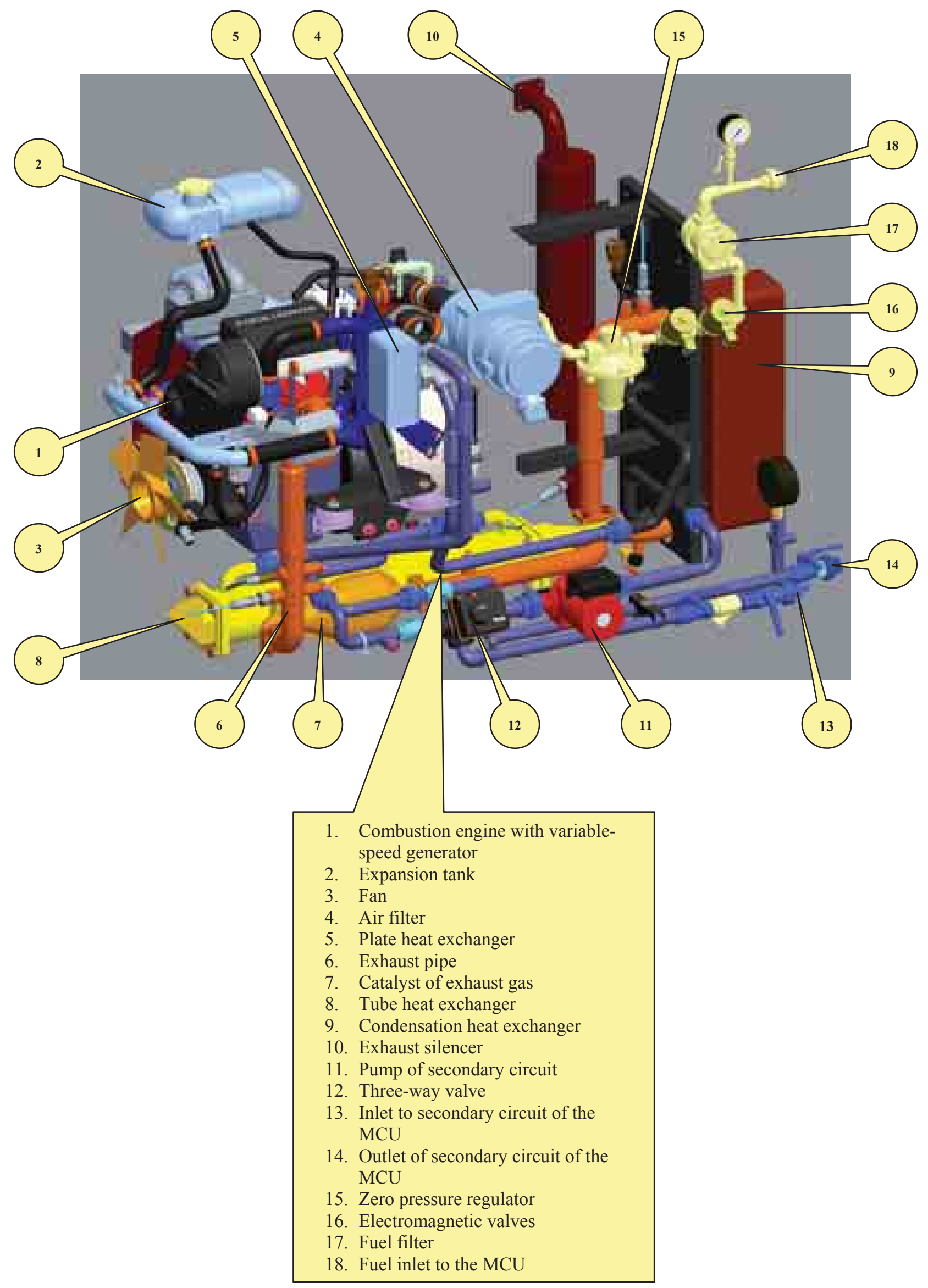

Fig. 9. Internal layout of the prototype of the micro-cogeneration unit without electronics 


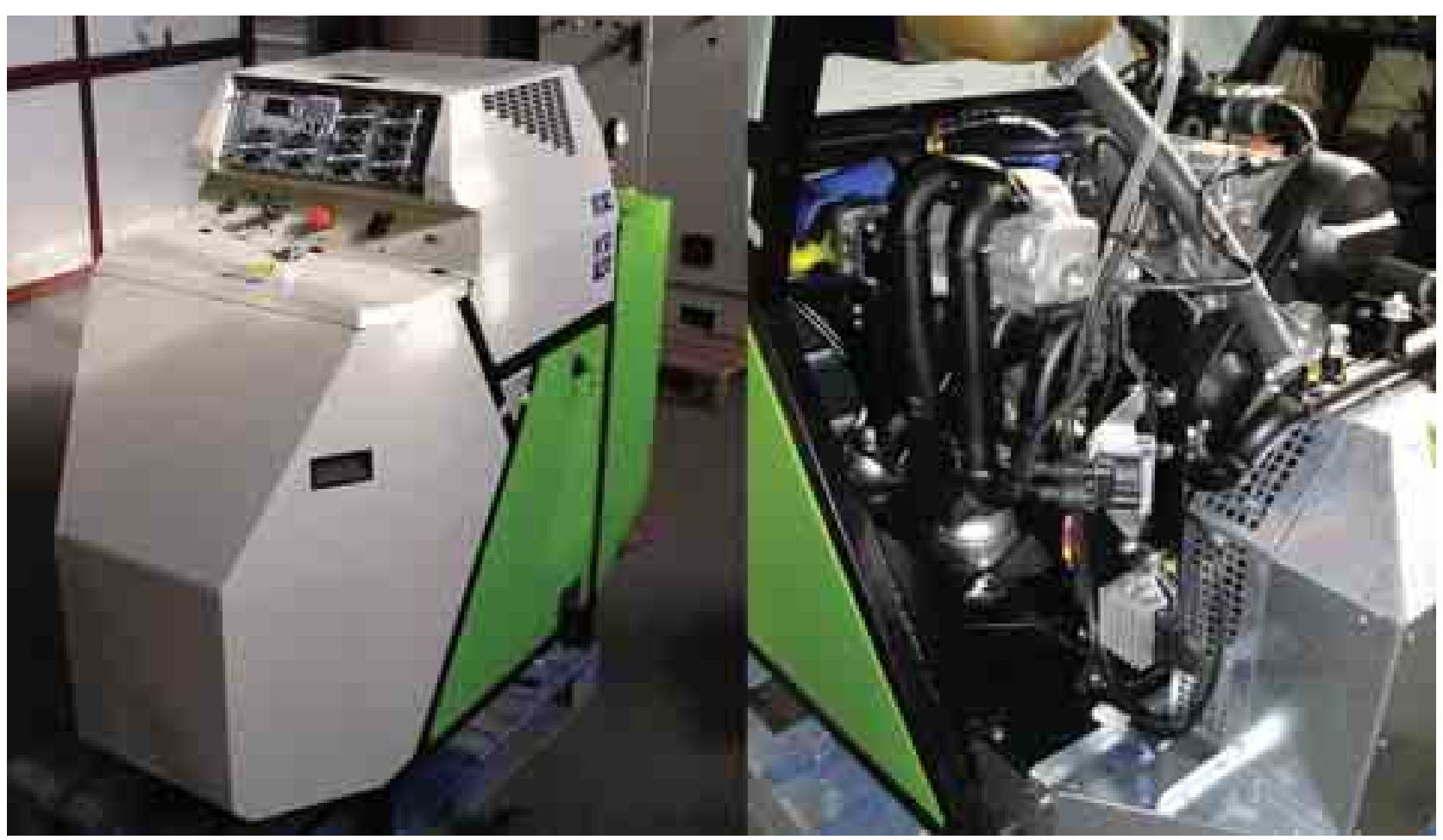

Fig. 10. Manufactured prototype of the micro-cogeneration unit (left) and an insight view of the engine with modified long intake pipes (right)

Tab. 3. Emission measurement behind catalytic converter from prototype of $M C U$

\begin{tabular}{|c|c|c|c|c|c|c|c|}
\hline $\mathrm{n}$ & $\mathrm{P}_{\mathrm{red}}$ & $\lambda$ & $\mathrm{CO}$ & $\mathrm{CO}_{2}$ & $\mathrm{CH}_{\mathrm{x}}$ & $\mathrm{NO}_{\mathrm{x}}$ & $\mathrm{O}_{2}$ \\
\hline$\left[\mathrm{min}^{-1}\right]$ & {$[\mathrm{kW}]$} & {$[-]$} & {$[\%]$} & {$[\%]$} & {$[\mathrm{ppm}]$} & {$[\mathrm{ppm}]$} & {$[\%]$} \\
\hline 3000 & 13.2 & 0.998 & 0.003 & 11.72 & 22 & 3 & 0.01 \\
\hline 2500 & 11.5 & 0.998 & 0.004 & 11.71 & 30 & 28 & 0.03 \\
\hline 2200 & 9.6 & 0.999 & 0.004 & 11.70 & 35 & 75 & 0.05 \\
\hline 2000 & 8.8 & 1.000 & 0.005 & 11.70 & 22 & 28 & 0.07 \\
\hline 1800 & 8.1 & 1.001 & 0.005 & 11.71 & 17 & 0 & 0.06 \\
\hline 1600 & 7.4 & 1.000 & 0.005 & 11.69 & 22 & 0 & 0.07 \\
\hline 1500 & 6.9 & 1.002 & 0.004 & 11.63 & 29 & 0 & 0.12 \\
\hline 1300 & 6.1 & 0.998 & 0.007 & 11.69 & 76 & 3 & 0.12 \\
\hline
\end{tabular}

Tab. 4. Electric, thermal and total efficiency of MCU under different electric loads

\begin{tabular}{|c|c|c|c|c|c|}
\hline \multicolumn{7}{|c|}{ Micro-cogeneration unit (MCU) } & with variable-speed generator \\
\hline $\begin{array}{c}\text { electric power } \\
\text { of MCU }\end{array}$ & $\begin{array}{c}\text { thermal power } \\
\text { of MCU }\end{array}$ & $\begin{array}{c}\text { electric } \\
\text { efficiency of } \\
\text { MCU }\end{array}$ & $\begin{array}{c}\text { thermal } \\
\text { efficiency of } \\
\text { MCU }\end{array}$ & $\begin{array}{c}\text { total efficiency } \\
\text { of MCU }\end{array}$ & $\begin{array}{c}\text { volumetric } \\
\text { CNG } \\
\text { consumption }\end{array}$ \\
\hline$P_{\text {el }}[\mathrm{kWe}]$ & $P_{t h}[\mathrm{kWt}]$ & $\eta_{\text {el }}[\%]$ & $\eta_{t h}[\%]$ & $\eta_{t o t}[\%]$ & $M_{v g}\left[\mathrm{~m}^{3} / \mathrm{h}\right]$ \\
\hline 7.0 & 18.8 & 25.0 & 67.2 & 92.2 & 3.0 \\
\hline 6.0 & 17.6 & 24.7 & 66.5 & 91.1 & 2.8 \\
\hline 4.5 & 13.3 & 24.8 & 64.8 & 89.6 & 2.2 \\
\hline
\end{tabular}


The converter has demonstrated its ability to work at revolutions $3000 \mathrm{~min}^{-1}$ and at input voltage $280 \mathrm{~V}$. The measured values of the efficiency of the converter are within $90-93 \%$. The horizon for the future adaptations of the converter will probably lead to a higher efficiency of the converter to values around $95 \%$, circuit optimisation of the converter and improvement of firmware for energy supplies to distribution network.

4. The measurements (Tab. 4.) of complete micro-cogeneration unit, operating in island operation, have shown that the best electric efficiency is at $25 \%$, thermal efficiency reaches $65 \%$, out of which $10 \%$ is allotted to cooling the air and $55 \%$ to cooling the liquid. The overall (total) efficiency of the micro-cogeneration unit is higher than $90 \%$.

\section{Acknowledgements}

This work was supported by the Slovak Research and Development Agency under the contract No. APVV-0270-06 and under the contract No. APVV-0090-10.

\section{References}

[1] Research and Development of Microcogeneration Unit, Applied research for the Slovak Research and Development Agency under the contract no. APVV-0270-06, Bratislava, Slovakia.

[2] Polóni, M., Lach, J., Kálman, P., Daniž, M., The engine Lombardini LGW 702 with optimised valve timing and intake manifold, Research report. Slovak University of Technology in Bratislava, Faculty of Mechanical Engineering. Research report, (in Slovak language), May 2008.

[3] Polóni, M., Kálman, P., Lach, J., Smieško, Š., Lazar, L., Kunc, P., Jančošek, L., Microcogeneration Unit with Variable-Speed Generator. International Scientific Event Power Engineering 2010, Tatranské Matliare, High Tataras, Slovak Republic. $9^{\text {th }}$ International Scientific Conference: Energy-Ecology-Economy (EEE), Proceedings on CD, Paper address: $\mathrm{CD} /$ files/EEE/5/4, 22 p., 2010.

[4] Polóni, M., Kálman, P., Lach, J., Smieško, Š., Lazar, L., Kunc, P., Jančošek, L., Isteník, R., Research and development of micro-cogeneration unit, Final research report, ÚDTKDivision of automobiles, ships and combustion engines, Faculty of Mechanical Engineering STU in Bratislava, 194 p., In the frame of contract no. APVV-0270-06, (in Slovak language), July 2010. 